\title{
Rural and urban disparities in the care of Canadian patients with inflammatory bowel disease: a population-based study
}

This article was published in the following Dove Press journal:

Clinical Epidemiology

Eric I Benchimol, ${ }^{1-5}$ M Ellen Kuenzig, ${ }^{1,2,5}$ Charles N Bernstein, ${ }^{6,7}$ Geoffrey C Nguyen, ${ }^{5,8}$ Astrid Guttmann, ${ }^{5,9}$ Jennifer L Jones, ${ }^{10}$ Beth K Potter, ${ }^{4}$ Laura E Targownik, ${ }^{6,7}$ Christina A Catley, ${ }^{5}$ Zoann J Nugent, ${ }^{6,11}$ Divine Tanyingoh, ${ }^{12,13}$ Nassim Mojaverian, ${ }^{5}$ Fox E Underwood, ${ }^{12,13}$ Shabnaz Siddiq, ${ }^{1,2}$ Anthony R Otley, ${ }^{14}$ Alain Bitton, ${ }^{15}$ Matthew W Carroll, ${ }^{16}$ Jennifer $C$ deBruyn, ${ }^{17}$ Trevor JB Dummer, ${ }^{18}$ Wael El-Matary, ${ }^{19}$ Anne M Griffiths, ${ }^{9}$ Kevan Jacobson, ${ }^{20,21}$ Desmond Leddin, ${ }^{10}$ Lisa M Lix, ${ }^{22}$ David R Mack, ${ }^{1-3}$ Sanjay K Murthy, ${ }^{4,23}$ Juan Nicolás Peña-Sánchez, ${ }^{24}$ Harminder Singh, ${ }^{6,7}$ Gilaad G Kaplan ${ }^{12,13}$

On behalf of the Canadian Gastro-Intestinal Epidemiology Consortium

'Children's Hospital of Eastern Ontario IBD Centre, Division of Gastroenterology, Hepatology and Nutrition, Children's Hospital of Eastern Ontario, Ottawa, Canada; ${ }^{2}$ Children's Hospital of Eastern Ontario Research Institute, Ottawa, Canada; ' ${ }^{D}$ epartment of Pediatrics, University of Ottawa, Ottawa, Canada; ${ }^{4}$ School of Epidemiology and Public Health, University of Ottawa, Ottawa, Canada; IICES, Toronto, Canada; 'University of Manitoba IBD Clinical and Research Centre, University of Manitoba, Winnipeg, Canada; 'Department of Internal Medicine, University of Manitoba, Winnipeg, Canada ${ }^{8}$ Department of Medicine, Mount Sinai Hospital Centre for Inflammatory Bowel Disease, University of Toronto, Toronto, Canada; ' Department of Paediatrics, University of Toronto, Toronto, Canada; ${ }^{10}$ Department of Medicine, Dalhousie University, Halifax, Canada; "CancerCare Manitoba, Winnipes Canada; '2Department of Medicine, University of Calgary, Calgary, Alberta, Canada; ${ }^{13}$ Department of Community Health Sciences, University of Calgary, Calgary, Alberta, Canada: ${ }^{14}$ Department of Pediatrics, Dalhousie University, Halifax Canada; ${ }^{5}$ Division of Gastroenterology, McGill University Health Centre, Montreal, Canada; ' ${ }^{6}$ Division of Pediatric Gastroenterology and Nutrition, Department of Pediatrics, University of Alyerta, Edmonton Danda; ${ }^{17}$ Division of University or Alberta, Edmonton, Canada," "Division of Gastroenterology, Department of Pediatrics, University of Calgary, Calgary, Canad, 'School or Population and Public

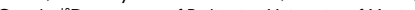
Canada, "Department of Pediatrics, University of Manitoba, Winnipeg, Canada, "Department of Pediatrics, The University of British Columbia, British Columbia, Canada; ${ }^{2}$ Child and Family Research Institute, The University of British Columb British Columbia, Canada; ${ }^{22}$ Department of Community Health Sciences, University of Manitoba, Winnipeg, Canada; ${ }^{23}$ The Ottawa Hospital IBD Centre, Department of Medicine, University of Ottawa, Ottawa, Ontario, Canada; ${ }^{24}$ Departmen of Community Health and Epidemiology, University of Saskatchewan, Saskatoon, Canada

Corresponghol Eric I Benchimol

Division of Gastroenterology, Hepatology and Nutrition, Children's Hospital of Eastern Ontario IBD Centre, 40I Smyth Road, Ottawa, ON KIH 8LI, Canada

$\mathrm{Tel}+\mathrm{I} 6137377600 \mathrm{ext} \mid 516$

$\mathrm{Fax}+\mathrm{I} 6137384854$

Email ebenchimol@cheo.on.ca

Background and aims: Canada's large geographic area and low population density pose challenges in access to specialized health care for remote and rural residents. We compared health services use, surgical rate, and specialist gastroenterologist care in rural and urban inflammatory bowel disease (IBD) patients in Canada.

Methods: We used validated algorithms that were applied to population-based health administrative data to identify all people living with the following three Canadian provinces: Alberta, Manitoba, and Ontario (ON). We compared rural residents with urban residents for time to diagnosis, hospitalizations, outpatient visits, emergency department (ED) use, surgical rate, and gastroenterologist care. Multivariable regression compared the outcomes in rural/urban patients, controlling for confounders. Provincial results were meta-analyzed using random-effects models to produce overall estimates.

Results: A total of 36,656 urban and 5,223 rural residents with incident IBD were included. Outpatient physician visit rate was similar in rural and urban patients. IBD-specific and IBDrelated hospitalization rates were higher in rural patients (incidence rate ratio [IRR] 1.17, 95\% CI 1.02-1.34, and IRR 1.27, 95\% CI 1.04-1.56, respectively). The rate of ED visits in ON were similarly elevated for rural patients (IRR $1.53,95 \%$ CI $1.42-1.65$, and IRR $1.33,95 \%$ CI $1.25-1.40)$. There were no differences in surgical rates or prediagnosis lag time between rural and urban patients. Rural patients had fewer IBD-specific gastroenterologist visits (IRR 0.79, 95\% CI 0.73-0.84) and a smaller proportion of their IBD-specific care was provided by gastroenterologists $(28.3 \%$ vs $55.2 \%, P<0.0001)$. This was less pronounced in children $<10$ years at diagnosis $(59.3 \%$ vs $65.0 \%, P<0.0001)$, and the gap was widest in patients $>65$ years $(33.0 \%$ vs $59.2 \%, P<0.0001)$.

Conclusion: There were lower rates of gastroenterologist physician visits , more hospitalizations, and greater rates of ED visits in rural IBD patients. These disparities in health services use result in costlier care for rural patients. Innovative methods of delivering gastroenterology care to rural IBD patients (such as telehealth, online support, and remote clinics) should be explored, especially for communities lacking easy access to gastroenterologists.

Keywords: inflammatory bowel disease, epidemiology, health services research, access to care, health administrative data, routinely collected health data

\section{Introduction}

Canada has a universal health care system, in which all legal residents receive essential medical services paid by provincial governments, including outpatient, emergency, and inpatient services. A founding principle of the Canada Health Act is universality, entitling all Canadians to the same level and quality of health care. ${ }^{1}$ Nevertheless, disparities in access to care, health services utilization, and outcomes exist. For example, children 
with inflammatory bowel disease (IBD) living in Ontario (ON) were more likely to undergo intestinal resection or colectomy if they lived in lower income households ${ }^{2}$ and adults with IBD living in $\mathrm{ON}$ with public drug insurance plans were less likely to receive biologics than those with private drug insurance. ${ }^{3} \mathrm{~A}$ population-based study from $\mathrm{ON}$ demonstrated that the only statistically significant predictor of need for repeated intestinal resections for Crohn's disease (CD) was rural residence at the time of diagnosis. ${ }^{4}$ Describing variation in care in order to identify health disparities is a crucial step toward improving the quality of care to patients and to moving health care toward the principle of universality. ${ }^{5-7}$

Canada is the second largest country in the world (9.985 million $\mathrm{km}^{2}$ ) and has one of the lowest population densities (4 people $/ \mathrm{km}) .{ }^{28}$ As such, health care providers and policy makers are tasked with providing universal access to health services and equal quality of care to people spread over a very large geographic region. This has led to concern that people living in remote regions may receive worse care than those in large, urban centers..$^{9}$ Moreover, persons with complex chronic diseases require access to specialized care generally only available in urban areas. Poor access to specialized care has been associated with suboptimal outcomes in various chronic disease states, including those people with IBD. ${ }^{10}$

IBD and its subtypes CD and ulcerative colitis (UC) are chronic inflammatory diseases of the gastrointestinal tract. IBD can present at any age, but the peak incidence is in the second or third decade of life. As a result, patients with IBD require health care throughout their lives. In addition, Canada is among the highest prevalence and incidence rates of IBD in the world, ${ }^{11-13}$ and the incidence is rising rapidly in young children, ${ }^{14}$ suggesting an increasing burden on the health system in the future. ${ }^{15,16}$ In this study, we used population-based health administrative data to examine disparities in the use of health services and access to care in three Canadian provinces (Alberta [AB], Manitoba [MB], and ON), comprising $53.9 \%$ (19.5 million people) of the Canadian population. ${ }^{17} \mathrm{We}$ assessed whether disparities in care and outcomes (including surgery) existed for rural and urban residences.

\section{Methods}

\section{Study design, setting, and participants}

This study was approved by research ethics boards of the University of Calgary, University of Manitoba, and Children's Hospital of Eastern Ontario. We conducted a populationbased, retrospective cohort study using health administrative data from $\mathrm{AB}, \mathrm{MB}$, and $\mathrm{ON}$, Canada, to compare 1) health services utilization (ie, outpatient physician visits, hospitalizations, and emergency department [ED] visits), 2) risk of surgery, 3) time to diagnosis, and 4) use of specialist gastroenterologists in people with IBD living in rural or urban residences. Health administrative data in Canada contain all residents of the province in question who qualified for universal government health care insurance $(>99 \%$ of the population). We included all residents who were diagnosed with IBD in fiscal year 1999-2010 (April 1, 1999, to March 31, 2011) (for MB and ON) or 1999-2008 (for AB). We excluded residents without a valid postal code in the year of diagnosis or the year prior to diagnosis. We also excluded residents for whom rural/urban classification of the residence could not be ascertained from postal code. All data are anonymized using encrypted health card numbers to produce a unique identification number for each resident of a province. Individuals are then linked deterministically across health administrative and demographic databases using this unique identifier.

\section{Definition of rural/urban status}

Residents were assigned a category of rural/urban status based on their postal code in the year of diagnosis. Different definitions have been used in Canada to classify the population according to rural/urban residence. ${ }^{18}$ We chose a definition that was validated to reflect the proportion of people in rural/urban residences in Canada according to Statistics Canada. ${ }^{19}$ This definition assigns urban status based on residence in a metropolitan area or in a 'Census Agglomeration Influenced Zone' (MIZ), which incorporates the level of influence that metropolitan areas exert upon nonmetropolitan areas (ie, areas that are outside of cities, but where a substantial proportion of the population commutes to the city for work, are considered urban). Those individuals not residing in a metropolitan area or MIZ were considered to be rural (rural/urban status was considered dichotomous).

\section{Outcomes of interest}

\section{Health services utilization}

We determined IBD-specific and IBD-related outpatient physician, hospitalization, and ED visit rates. ED utilization data were only available for ON. We evaluated whether health services utilization after diagnosis was associated with rural/urban residence at diagnosis. IBD-specific visits were those associated with ICD codes for CD and UC (ICD-9 555.x/556.x or ICD-10 K50.x/K51.x). IBD-related contacts were those associated with IBD-specific diagnoses or visits with diagnoses of signs and symptoms of IBD (Table S1). 
These code lists have been used in previous studies..$^{20,21}$ Only hospitalizations in which the $\mathrm{CD}$ or UC diagnosis was the reason for, or contributed to, the hospitalization were included.

\section{Surgery}

We determined surgical outcomes stratified by IBD subtype, including intestinal resection or colectomy for $\mathrm{CD}$ and colectomy for UC patients. In the case of CD patients, we also evaluated the risk of undergoing repeated intestinal resection surgery if one surgery was already performed. We determined whether surgical risk following diagnosis was associated with rural/urban residence at diagnosis. Codes used to identify IBD surgeries from within Canadian hospital data were previously validated (Table $\mathrm{S} 2$ ). ${ }^{22,23}$

\section{Prediagnosis lag time}

For prediagnosis contacts, we determined the time (in days) from the first outpatient or inpatient visit associated with a code determined to be likely related to subsequent diagnosis of IBD and the date of diagnosis (assigned as the first outpatient or inpatient visit with an ICD diagnostic code for $\mathrm{CD}$ or $\mathrm{UC}$ ). Time to diagnosis was measured using the health services diagnostic codes in the 5 years prior to diagnosis by determining the time from first IBD-associated diagnosis code to the date of first outpatient or inpatient IBD-specific diagnostic code. Codes used in the prediagnosis period (Supplementary materials) were determined by surveys of expert adult and pediatric gastroenterologists that were used in previous studies. ${ }^{24}$

\section{Specialist gastroenterologist care}

Specialist physician visits were classified based on outpatient billing patterns and certification status. We classified visits as those conducted by gastroenterologists or nongastroenterologists (including surgeons, internists, pediatricians, family physicians, and other specialists). Not all physicians functioning as gastroenterologists were certified as such. For example, some internists were trained and worked as gastroenterologists but completed their training before specialist gastroenterology examination and certification were available. Therefore, internists who performed $>50$ annual colonoscopies and pediatricians who performed $>5$ annual colonoscopies were classified as gastroenterologists. ${ }^{20}$

In order to determine whether the use of specialist physician care mediated the association between rural/urban residence and disparities in health services utilization, we conducted additional analyses using ON data only. We determined the association between rural/urban residence and risk or rates of health services utilization or surgery following diagnosis while controlling for the following three separate models: 1) specialty of the physician providing most IBD-specific care (gastroenterologist or nongastroenterologist; dichotomous); 2) the proportion of IBD-specific care provided by a gastroenterologist (continuous proportion); and 3) ever having seen a gastroenterologist for IBD-specific care (yes or no; dichotomous).

\section{Data sources}

We used health administrative data from the following three Canadian provinces: AB (1999-2008), MB (1999-2010), and ON (1999-2010). We used cohorts of all IBD patients living in each province identified by using validated algorithms of health care contacts to identify patients with IBD and to classify their disease as CD, UC, or IBD type unclassifiable. IBD type unclassifiable represent patients for whom the algorithms based on health services patterns and codes could not effectively distinguish whether they had CD or UC. This group was called unclassifiable in $\mathrm{AB}$ and $\mathrm{ON}$ only, whereas all patients in MB were considered either CD or UC. Validated washout periods were used to distinguish incident cases from prevalent cases. These cohorts included the Alberta IBD Surveillance Cohort ${ }^{25}$ the University of Manitoba IBD Epidemiology Database, ${ }^{26}$ and the Ontario Crohn's and Colitis Cohort. ${ }^{27,28}$ The cohorts used algorithms validated in their respective province to identify and classify patients with IBD. Table S3 includes information on each cohort, the accuracy of the algorithms used, and information on the source, database, and study populations. This table also includes information on health administrative data used to identify subjects and derive their socio-demographic characteristics. In all provinces, the entire IBD population was available to investigators for analysis.

Postal codes were taken from Statistics Canada's Postal Code Conversion File (PCCF) ${ }^{29}$ Information on hospitalizations and surgeries was derived from reports to the Canadian Institute for Health Information (CIHI), with diagnostic codes $92 \%-99 \%$ accurate ${ }^{30}$ Surgical codes were validated in this database for patients with $\mathrm{UC}^{22,31}$ and $\mathrm{CD}^{23}$ Outpatient physician visit data were obtained from physician billing information from Alberta Health, Manitoba Health, and Ontario Health Insurance Plan (OHIP) data. ED utilization data were derived from OHIP (available only for ON). To control the confounding by socioeconomic status, we used the mean neighborhood income quintile derived from postal codes using the PCCF Plus. ${ }^{32}$

Specialist physician visits were classified using the classification provided by Alberta Health data, Manitoba Health data, and the Institute for Clinical Evaluative Sciences (ICES) Physician Database for Ontario. ${ }^{33}$ We classified visits as those 
conducted by gastroenterologists or nongastroenterologists (including surgeons, internists, pediatricians, family physicians, and other specialists).

\section{Statistical analysis}

Descriptive statistics is presented as mean (with SD) or median (with IQR). Multivariable regression models tested the association between rural/urban residence at diagnosis and outcomes (outpatient visit rates, hospitalization rates, risk of hospitalization, ED visit rates, risk of surgery, likelihood of multiple surgeries, prediagnosis time, and specialist care). All models included the binary rural/urban predictor along with predetermined a priori potential confounders of sex (male or female), age at diagnosis (continuous variable), and mean neighborhood income quintile (categorical variable), a validated proxy for individual-level socioeconomic status. ${ }^{34}$

Outpatient physician visits were modeled assuming a Poisson distribution, with the natural log of years of follow-up as the offset. Due to their low annual rates, hospitalizations and ED visits did not follow a Poisson distribution. Therefore, these were modeled using negative binomial regression. The risks of hospitalization, ED visit, and surgery were estimated using Cox proportional hazard models. The proportionality assumption was considered met when the rural/urban variable was determined not to be a time-dependent covariate even if other covariates violated the assumption.

A multivariable negative binomial regression model was used to test the association between rural/urban residence and specialist care; the latter was measured using the annual number of visits to a gastroenterologist and was determined using the negative binomial regression. The proportion of care provided by gastroenterologists (as compared to other specialties) was compared using a univariate Chi-squared analysis. The likelihood of ever having seen a gastroenterologist for IBD-related reasons in rural/urban patients was compared using the multivariable logistic regression analysis. Due to a statistically significant interaction between age at diagnosis and rural/urban status in $\mathrm{ON}$, all specialist care analyses were stratified by age group at diagnosis (overall, <10, 10-17.9, 18-39.9, 40-64.9, and $\geq 65$ years). We did not report models with the interaction term included due to the difficulty reporting the strength of association between rural/urban status and outcome existed.

To test the association between rural/urban residence and the risk of IBD diagnostic delay, we used retrograde multivariable Cox proportional hazard models, ${ }^{35-37}$ where date of diagnosis was the start and prediagnosis time to the first related visit was the time to event. The proportionality assumption was met based on the above method of testing.
To determine whether physician specialist care (gastroenterologist or not) mediated the association between rural/ urban residence and health services use in $\mathrm{ON}$, regression models (Poisson, Cox proportional hazard, or negative binomial) were repeated, controlling for 1) care provision; 2 ) rural/urban; 3) age at IBD diagnosis (0-9, 10-17, 18-39, $40-64$, and $\geq 65$ years); 4) sex (male or female); and 5) mean neighborhood income quintile. Care provision was defined in the following three ways in three separate models: 1) gastroenterologist or nongastroenterologist as the primary provider of $\geq 50 \%$ of IBD-specific care (dichotomous); 2) proportion of care provided by a gastroenterologist (continuous); and 3 ) ever having seen a gastroenterologist (dichotomous). For the proportion of IBD care provided by a gastroenterologist (continuous), we assigned each neighborhood (using threedigit postal code as the spatial unit) to a quintile of proportion of care provided by a gastroenterologist within each province. We then constructed a heat map to visualize whether higher proportion of care quintile was associated with urban areas.

In order to report overall associations across multiple provinces, we conducted a meta-analysis across provinces using random-effects models, which provide more conservative estimates than fixed-effect models. Meta-analysis of provincial data used stratified incidence rate ratio (IRR) for count data, OR for dichotomous data, and HR for time-to-event data. This has been demonstrated to be an effective method of combining rate data that accounts for heterogeneity. ${ }^{38}$ When pooling the results of the descriptive statistics (median, mean) or regression models, each result was weighted by the inverse of its variance. Heterogeneity was tested using the $I^{2}$ statistic and Cochran Chi-squared test ( $Q$ test), which describe the percentage of total variation across incidence estimates due to heterogeneity rather than chance. Analyses were conducted using SAS Version 9.3 (SAS Institute Inc., Cary, NC, USA). Meta-analyses were conducted using Stata release 14 (StataCorp LP, College Station, TX, USA) and R version 3.4.2 (R Foundation for Statistical Computing, Vienna, Austria) using the "metafor" package. ${ }^{39}$ All tests of statistical significance were conducted using a nominal $\alpha=0.05$.

\section{Results}

\section{Descriptive characteristics}

Among all provinces, 41,879 patients with IBD were included in the study $(5,223$ from rural residences and 36,656 from urban residences). The descriptive characteristics of the cohort are noted in Table 1. IBD patients in MB were more likely to live in rural residences $(24.4 \%)$, compared to $\mathrm{AB}$ $(19.3 \%)$ and $\mathrm{ON}(9.7 \%)(P<0.0001)$. The IBD population was 
Table I Descriptive characteristics of rural and urban patients with IBD

\begin{tabular}{|c|c|c|c|c|c|c|c|c|c|}
\hline \multirow[t]{2}{*}{ Characteristics } & \multicolumn{2}{|l|}{ Alberta } & \multicolumn{2}{|l|}{ Manitoba } & \multicolumn{2}{|l|}{ Ontario } & \multicolumn{3}{|l|}{ Overall } \\
\hline & $\begin{array}{l}\text { Rural } \\
(n=1,6 \mid 3)\end{array}$ & $\begin{array}{l}\text { Urban } \\
(n=6,7 \mid 5)\end{array}$ & $\begin{array}{l}\text { Rural } \\
(n=583)\end{array}$ & $\begin{array}{l}\text { Urban } \\
(n=I, 803)\end{array}$ & $\begin{array}{l}\text { Rural } \\
(n=3,027)\end{array}$ & $\begin{array}{l}\text { Urban } \\
(n=28,138)\end{array}$ & $\begin{array}{l}\text { Rural } \\
(n=5,223)\end{array}$ & $\begin{array}{l}\text { Urban } \\
(n=36,656)\end{array}$ & $P$-value \\
\hline $\begin{array}{l}\text { Age at diagnosis } \\
\text { (years), mean } \pm S D\end{array}$ & $42.8 \pm 18.8$ & $40.3 \pm 18.8$ & $42.8 \pm 18.7$ & $40.6 \pm 19.2$ & $45.1 \pm 18.7$ & $39.8 \pm 18.8$ & $44.1 \pm 18.8$ & $39.9 \pm 18.8$ & $<0.0001$ \\
\hline Female sex, n (\%) & $823(51.0)$ & $3,525(52.5)$ & $302(5 \mid .8)$ & $28 I(48.2)$ & $\mathrm{I}, 585(53.4)$ & $14,482(5 \mid .6)$ & $2,710(51.9)$ & I8,288 (49.9) & 0.49 \\
\hline $\begin{array}{l}\text { Length of follow-up } \\
\text { (years), mean } \pm \text { SD }\end{array}$ & $15.2 \pm 2.0$ & $15.2 \pm 2.0$ & $7.4 \pm 3.5$ & $7.5 \pm 3.4$ & $7.1 \pm 3.5$ & $7.2 \pm 3.4$ & $6.7 \pm 3.3$ & $7.0 \pm 3.3$ & $<0.0001$ \\
\hline \multicolumn{10}{|l|}{ Diagnosis, n (\%) } \\
\hline$C D$ & $747(46.3)$ & $3,039(45.3)$ & $265(45.5)$ & 809 (44.9) & $\mathrm{I}, 276(42.2)$ & I2,767 (45.4) & $2,288(43.8)$ & 16,615 (45.3) & \multirow[t]{3}{*}{$<0.0001$} \\
\hline UC & $524(32.5)$ & $2,443(36.4)$ & $318(54.6)$ & $994(55.1)$ & $\mathrm{I}, 56 \mathrm{I}(5 \mathrm{I} .6)$ & I3,788 (49.0) & $2,403(46.0)$ & $17,225(47.0)$ & \\
\hline Unclassifiable & $342(21.2)$ & $\mathrm{I}, 233(\mathrm{I} 8.4)$ & $\mathrm{n} / \mathrm{a}^{\mathrm{b}}$ & $\mathrm{n} / \mathrm{a}^{\mathrm{b}}$ & $190(6.3)$ & $\mathrm{I}, 583(5.6)$ & $532(10.2)$ & $2,816(7.7)$ & \\
\hline \multicolumn{10}{|c|}{ Mean neighborhood income quintile, $n(\%)$} \\
\hline I (lowest) & $274(17.1)$ & $\mathrm{I}, 486(22.1)$ & $101(17.4)$ & $247(13.8)$ & $592(19.6)$ & $4,238(15.1)$ & $\mathrm{I}, 000(\mathrm{I} 8.4)$ & $6,317(17.1)$ & \multirow[t]{6}{*}{$<0.0001$} \\
\hline 2 & $252(15.6)$ & $\mathrm{I}, 57 \mathrm{I}(23.4)$ & $146(25.1)$ & $282(15.8)$ & $649(21.4)$ & $5,403(19.2)$ & $\mathrm{I}, 12 \mathrm{I}(20.6)$ & $7,209(19.5)$ & \\
\hline 3 & $415(25.7)$ & $1,275(19.0)$ & $143(24.6)$ & $366(20.4)$ & $602(19.9)$ & $5,754(20.5)$ & $1,260(23.2)$ & $7,328(19.8)$ & \\
\hline 4 & $310(19.2)$ & $\mathrm{I}, 237(18.4)$ & $124(21.3)$ & $402(22.5)$ & $574(18.9)$ & $6,194(22.0)$ & $\mathrm{I}, 047(19.2)$ & $7,732(20.9)$ & \\
\hline 5 (highest) & $273(16.9)$ & $\mathrm{I}, \mathrm{I} 05(\mathrm{I} 6.5)$ & $68(11.7)$ & $494(27.6)$ & $584(19.3)$ & $6,496(23.1)$ & $862(15.9)$ & $8,235(22.2)$ & \\
\hline Unknown & $88(5.5)$ & $4 \mid(0.6)$ & $\mathrm{n} / \mathrm{a}$ & $\mathrm{n} / \mathrm{a}$ & $26(0.86)$ & $53(0.19)$ & $176(3.2)$ & $137(0.4)$ & \\
\hline
\end{tabular}

Notes: ${ }^{2}$ Comparing patients with rural vs urban residence. ${ }^{b}$ Manitoba assigns a diagnosis of CD or UC for all patients. No patient was considered unclassifiable. Abbreviations: CD, Crohn's disease; IBD, inflammatory bowel disease; n/a, not applicable; UC, ulcerative colitis.

less rural than the general population ${ }^{19}$ in $\mathrm{MB}(24.4 \%$ rural IBD population vs $28 \%$ rural general population, $P=0.0005$ ) and $\mathrm{ON}(9.7 \%$ vs $14 \%$, Chi-squared $P<0.0001)$ but not AB (19.3\% vs $17 \%, P<0.0001)$. Compared with urban IBD patients, rural patients with IBD were older $(44.1 \pm 18.7$ vs $39.9 \pm 18.8, P<0.0001)$, were less likely to have $\mathrm{CD}(43.8 \%$ vs $45.3 \%, P<0.0001)$, and were more likely to be of the lower income quintiles $(P<0.0001)$.

\section{Health services utilization}

Rates of IBD-specific outpatient physician visits were not significantly different in rural and urban patients for overall IBD (IRR 0.99, 95\% CI 0.94-1.04), CD (IRR 1.04, 95\% CI 0.99-1.09), or UC (IRR 0.94, 95\% CI 0.88-1.01) (Figure 1). There was no significant statistical heterogeneity when data from the three provinces were meta-analyzed ( $\mathrm{I}^{2} 50.0 \%$, $P=0.13)$. Rates of IBD-related outpatient visits were not significantly different in rural and urban patients (OR 0.99 , 95\% CI 0.92-1.07) with significant heterogeneity ( $I^{2} 83.1 \%$, $P<0.01)$; this was driven primarily by lower visit rates for $\mathrm{ON}$ rural UC patients (OR 0.87, 95\% CI 0.84-0.91).

Hospitalization rates were significantly higher in rural patients than in urban patients, for both IBD-specific (IRR $1.17,95 \%$ CI 1.02-1.34) and IBD-related (IRR 1.27, 95\% CI 1.04-1.56) hospitalizations (Figure 2). This difference was significant for CD (IBD-specific: IRR 1.15, 95\% CI 1.08 1.22; IBD-related: IRR $1.28,95 \%$ CI 1.09-1.49) but not for UC (IBD-specific: IRR 1.15, 95\% CI 0.92-1.44; IBD-related:
IRR $1.23,95 \%$ CI $0.96-1.58)$. There was significant heterogeneity across provinces (IBD-specific: $I^{2} 82.1 \%, P<0.01$; IBD-related: $\left.I^{2} 92.9 \%, P<0.01\right)$, with higher IBD-specific hospitalization rates in rural Albertans (IRR 1.11, 95\% CI 1.11-1.33) and Manitobans (IRR 1.31, 95\% CI 1.11-1.55) compared with those in rural ON patients (IRR 1.04, 95\% CI 0.97-1.11). The risk of ever being hospitalized for IBDspecific reasons was not significantly different in rural and urban patients (HR 1.09, 95\% CI 0.95-1.25) but was higher in rural patients for IBD-related reasons (HR 1.17, 95\% CI 1.021.33) (Figure 3).

In ON, ED visit rate was significantly higher in rural patients compared to that in urban patients for both IBDspecific reasons (IBD: IRR 1.53, 95\% CI 1.42-1.65; CD: IRR 1.74, 95\% CI 1.57-1.92; UC: IRR 1.26, 95\% CI 1.12-1.41) and IBD-related reasons (IBD: IRR 1.33, 95\% CI 1.25-1.40; CD: IRR 1.47, 95\% CI 1.36-1.59; UC: IRR $1.18,95 \%$ CI 1.09-1.28). Similarly, the risk of ever having visited the ED was higher in rural patients than in urban patients for IBD-specific reasons (IBD: IRR 1.23, 95\% CI 1.16-1.31; CD: IRR 1.26, 95\% CI 1.16-1.37; UC: IRR 1.21, 95\% CI 1.10-1.33) and IBD-related reasons (IBD: IRR 1.16, 95\% CI 1.11-1.21; CD: IRR 1.16, 95\% CI 1.08-1.24; UC: IRR $1.15,95 \%$ CI $1.08-1.23)$.

\section{Surgical outcomes}

The risk of requiring intestinal resection for $\mathrm{CD}$ was not different in rural and urban patients (HR 0.98, 95\% CI 


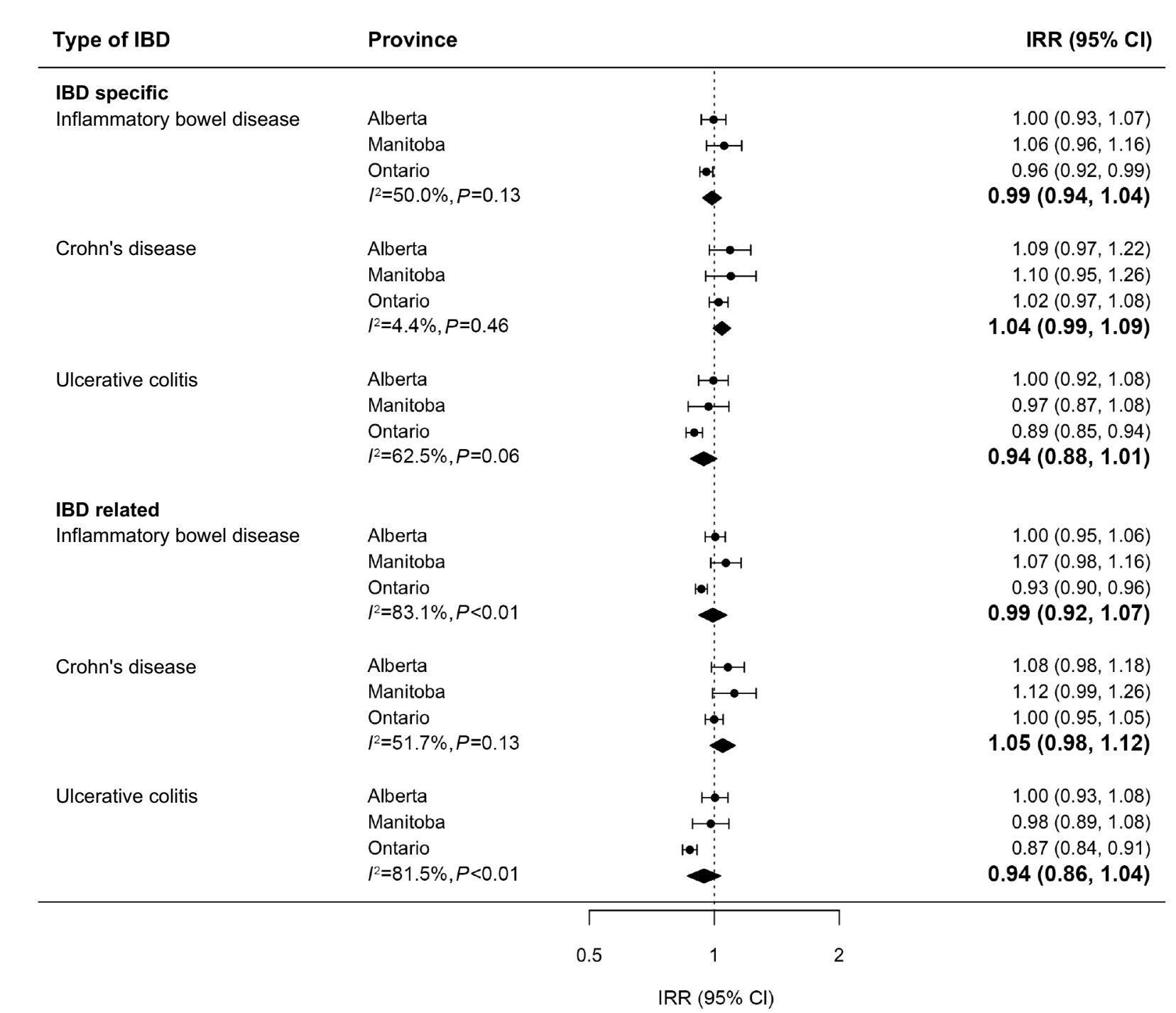

Figure I Association between rural and urban (reference) residences and IBD-specific and IBD-related outpatient visit rates (multivariable Poisson regression models). Abbreviations: IBD, inflammatory bowel disease; IRR, incidence rate ratio; Cl, confidence interval.

0.88-1.07), nor or was the risk of colectomy for UC (HR $0.92,95 \%$ CI $0.78-1.06$ ). The risk of surgery for $\mathrm{CD}$ and $\mathrm{UC}$ at $1,3,5$, and 10 years following diagnosis is displayed in Figure 4. For $\mathrm{CD}$ patients, there were significantly increased odds of having multiple (two or more) intestinal resection surgeries in rural patients compared with urban patients in ON only (OR 1.55, 95\% CI 1.16-2.08). There was no association between rural/urban and multiple surgeries in other provinces (AB: OR 1.14, 95\% CI 0.73-1.80; MB: OR 0.80, $95 \%$ CI $0.39-1.66$ ), resulting in no significantly increased risk overall (pooled OR 1.21, 95\% CI 0.79-1.63) and no significant statistical heterogeneity $\left(I^{2} 45.6 \%, P=0.16\right)$.

\section{Prediagnosis lag time}

For CD patients, there was no significant difference in diagnosis lag time between rural and urban patients (mean $187.4 \pm 235.0$ vs $175.8 \pm 229.4$ days; HR $1.01,95 \%$ CI
0.94-1.07), nor there was significant heterogeneity among provinces $\left(I^{2} 0 \%, P=0.72\right)$ (Figure 5). Rural UC patients also did not have significantly longer prediagnosis lag time compared to urban patients on multivariable regression analysis (HR 1.18, 95\% CI 0.97-1.45), and there was no significant heterogeneity $\left(I^{2} 66.1 \%, P=0.08\right)$ (Figure 5$)$. The mean time to diagnosis was also similar $(130.4 \pm 210.9$ vs $132.3 \pm 215.5$ days).

\section{Outpatient care by gastroenterologists}

In all analyses, rural patients were less likely to receive outpatient care from gastroenterologists for IBD-specific and IBD-related reasons. They had a lower odds of ever having an outpatient visit with a gastroenterologist after diagnosis (IBDspecific: OR 0.46, 95\% CI 0.32-0.65; IBD-related: OR 0.50, 95\% CI 0.37-0.68) (Figure 6). For IBD-specific visits, this association was not present for children $<10$ years at diagnosis 
Type of IBD

IBD-specific

Inflammatory bowel disease

Ulcerative colitis

BD-related

Inflammatory bowel disease

Crohn's diseas

Crohn's disease

Ulcerative colitis
Province

IRR $(95 \% \mathrm{Cl})$

Alberta
Manitoba
Ontario
$l^{2}=82.1 \%, P<0.01$
Alberta
Manitoba
Ontario
$l^{2}=0.0 \%, P=0.54$

Alberta

Manitoba

Ontario

$l^{2}=81.6 \%, P<0.01$

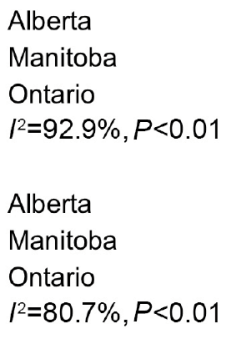

$I^{2}=80.7 \%, P<0.01$

Alberta
Manitoba
Ontario
$I^{2}=86.9 \%, P<0.01$

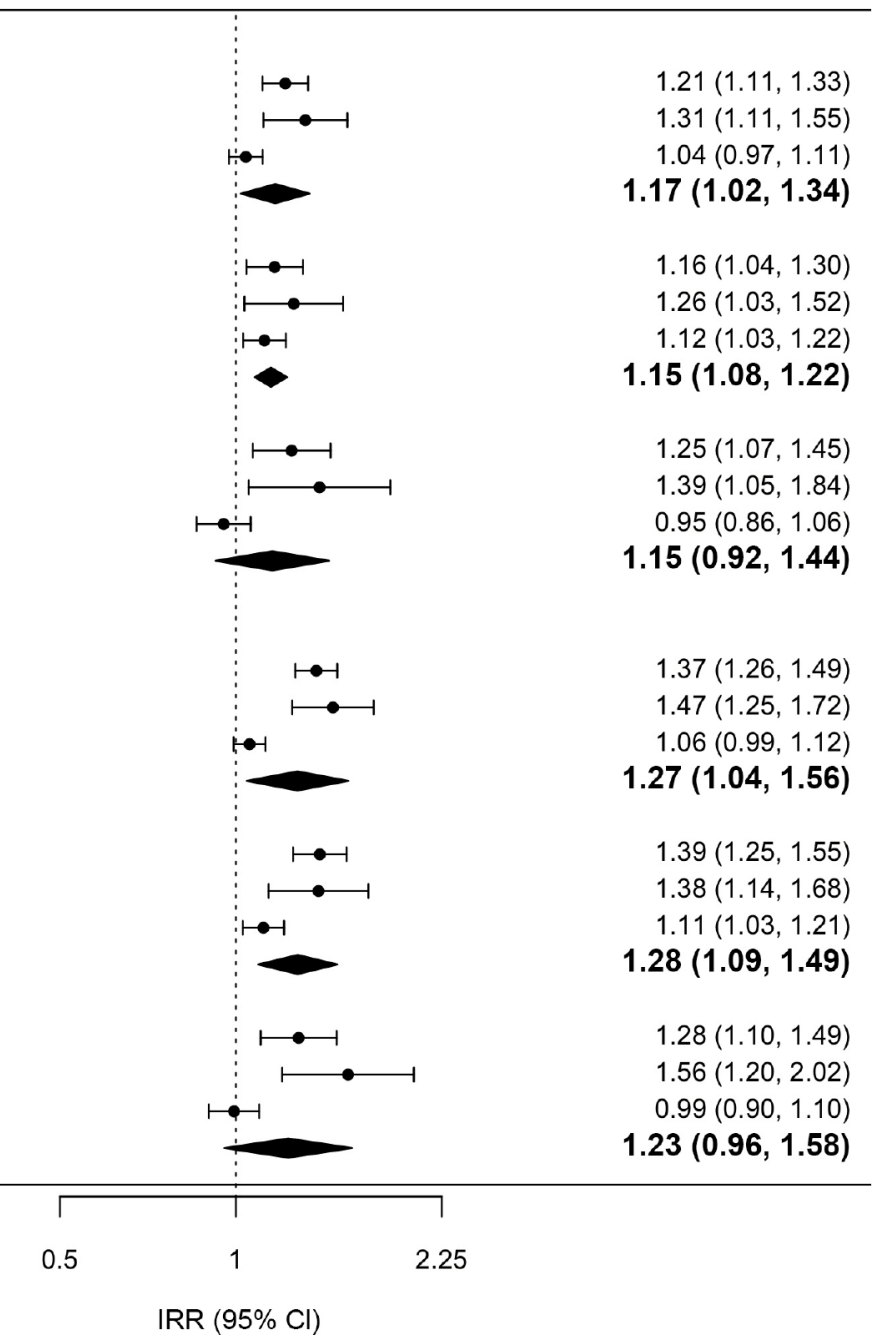

Figure 2 Association between rural and urban (reference) residences and IBD-specific and IBD-related hospitalization rates (multivariable negative binomial regression models). Bolded values represent meta-analysis results.

Abbreviations: IBD, inflammatory bowel disease; IRR, incidence rate ratio; $\mathrm{Cl}$, confidence interval.

(OR $0.97,95 \%$ CI $0.77-1.20$ ) or adolescents $10-18$ years at diagnosis (OR $0.70,95 \%$ CI $0.47-1.04$ ), but the association became much more prominent in older patients, especially those diagnosed $\geq 65$ years (OR 0.35 , 95\% CI $0.26-0.46$ ). Rural patients also had lower annual outpatient visit rates to gastroenterologists (IBD-specific: IRR 0.79 , 95\% CI 0.73-0.84; IBD-related: IRR 0.77, 95\% CI 0.69-0.85). This association was present across all age groups.

The proportion of IBD-specific outpatient visits to gastroenterologists was lower in rural patients than in urban patients $(28.3 \%$ vs $55.2 \%$, Chi-squared $P<0.0001)$. This was true across age groups but was less pronounced in children $<10$ years at diagnosis $(59.3 \%$ vs $65.0 \%, P<0.0001)$. The gap was most wide in patients $>65$ years $(33.0 \%$ vs $59.2 \%, P<0.0001)$. The heat map also demonstrates that neighborhoods with a higher proportion of care provided by gastroenterologists were more likely to be urban (Figure 7). Similarly, the proportion of IBD-related outpatient visits to gastroenterologists was lower in rural patients than in urban patients $(30.8 \%$ vs $47.7 \%, P<0.0001)$.

\section{Determination of whether specialist care mediates the relationship between rural/urban residence and health services disparities}

In $\mathrm{ON}$, physician specialist care (gastroenterologist or not) did not mediate the association between rural/urban residence and health services use, no matter which of the three definitions of specialist care was used. The results of analyses are presented in Table 2 . In all cases, including measures of 


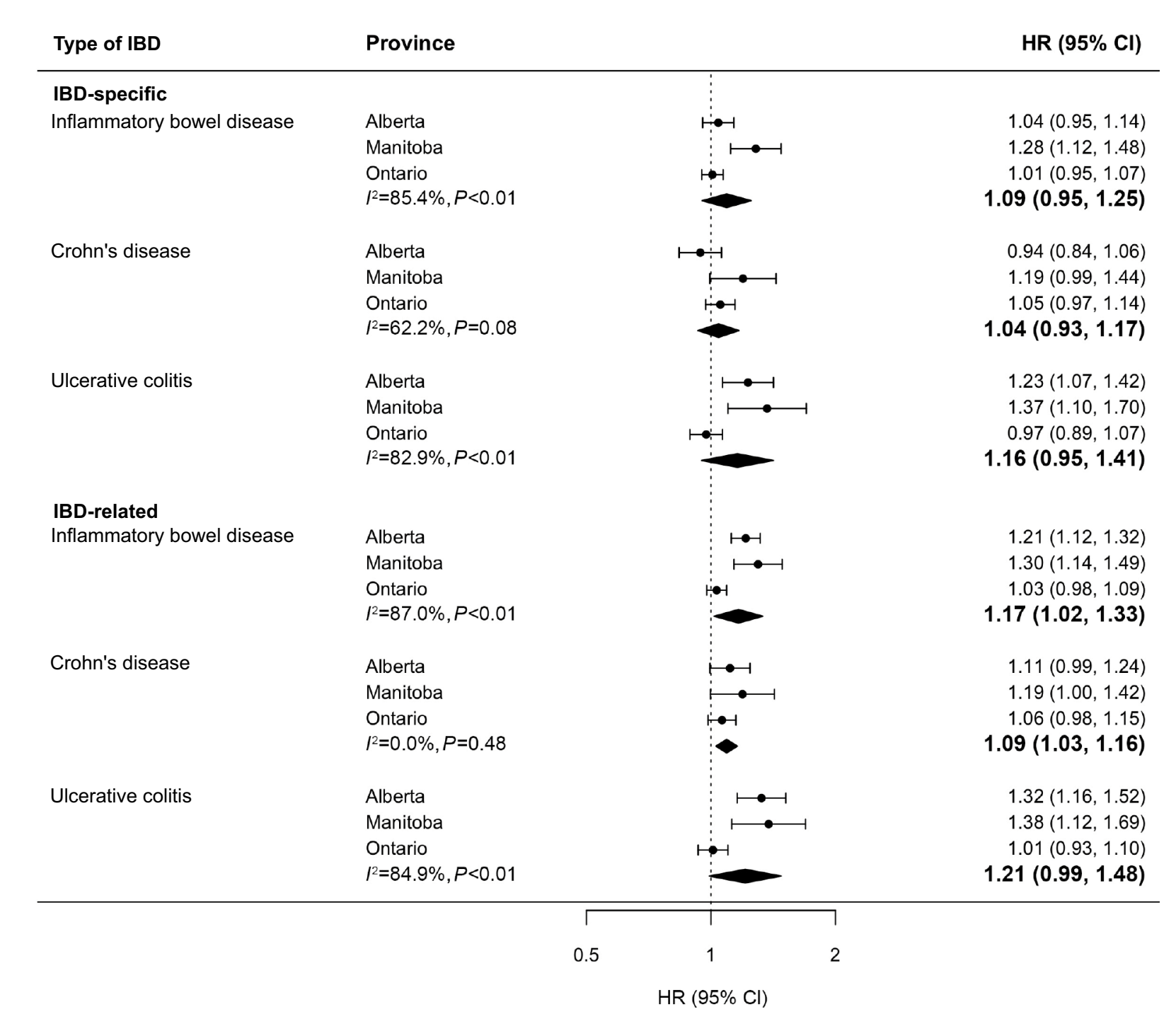

Figure 3 Association between rural and urban (reference) residences and risk of IBD-specific and IBD-related hospitalization (multivariable Cox proportional hazard models). Bolded values represent meta-analysis results.

Abbreviations: IBD, inflammatory bowel disease; IRR, incidence rate ratio.

specialist care changed the magnitude (IRR, OR, or HR) of association between rural/urban residence and health services utilization by $<10 \%$.

\section{Discussion}

In this multiprovince population-based study of health services utilization in patients with IBD living in Canada, we found selected disparities in care of patients living in rural and urban residences. Rural patients had higher hospitalization and ED visit rates compared with urban patients. In part, higher hospitalization and ED visits may be explained by rural patients being less likely to visit a gastroenterologist; as well, a smaller proportion of their care was provided by gastroenterologists as compared to urban residents. Limited access to specialist was observed across all ages but became more pronounced in older adults. In contrast, prediagnosis lag time and rates of outpatient visits were similar for rural and urban patients with IBD. While risk of first surgery was similar between urban and rural residents, ON patients with $\mathrm{CD}$ were more likely to undergo multiple surgical resections if they lived in rural communities. Collectively, these data highlight that access to specialist care is an important contributor to health care utilization and outcomes.

Very few studies have examined disparities in outcomes or health services use in rural and urban IBD patients. A recent study from the USA found that increased distance of IBD patients' home to a referral IBD center was associated with increased odds of surgery, biological use, and immunomodulator use. ${ }^{40}$ Every increase of 10 miles from the patients' home to the center resulted in a $9 \%$ increase 
in surgical risk and a $14 \%$ increase in the use of biological therapy ${ }^{40}$ Similarly, German patients with IBD were seen less frequently, were prescribed fewer medications, and were less likely to undergo surveillance colonoscopy if they lived in low-density or rural areas. ${ }^{41}$

We did not find similar disparities in remote patients in Canada, although population-based medication utilization data were not available for our population. We did not measure distance specifically; however, rural patients in Canada
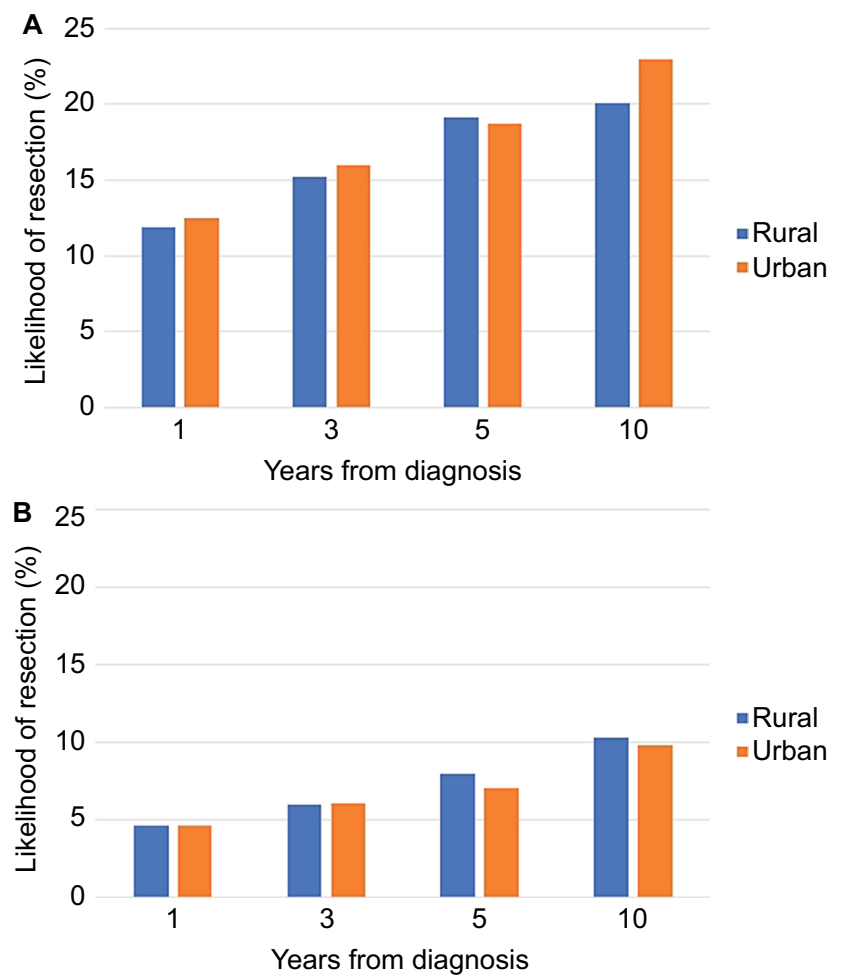

Figure 4 (A) Likelihood of resection or colectomy in rural and urban CD patients and (B) likelihood of colectomy in rural and urban UC patients.

Abbreviations: CD, Crohn's disease; UC, ulcerative colitis. typically live a greater distance to tertiary specialist care. ${ }^{42}$ In Canada, pediatric IBD care is more centralized than adult care, with urban pediatric health care centers housing the only pediatric gastroenterologists in most provinces. This may have resulted in less disparity in access to gastroenterologists in children compared with older adults, implying that there may be benefit to centralization in the pediatric IBD population (at least in terms of accessing specialist gastroenterologists). Alternatively, families with children with IBD may be more willing to travel long distances to receive specialist care. Conversely, elderly rural patients had very low rates of visits to gastroenterologists. These patients may be less willing to travel long distances to see gastroenterologists, or they may have less severe disease. This finding is a concern, considering that previous studies have demonstrated improved outcomes in adults with IBD who receive most of their care by gastroenterologists. ${ }^{43,44}$ However, we assessed whether various measures of gastroenterologist care provided for IBD mediated the association between rural/urban residence and health services utilization in ON. Including measures of gastroenterologist care provision in the models did not seem to alter the association (or lack thereof) for outpatient visits, hospitalization, or ED utilization.

Little is known about rurality as a predictor of disparities of care in chronic diseases. Remote ON diabetes patients were demonstrated to have increased rates of admissions and ED visits. ${ }^{10}$ General health care use was noted to be different for all residents of Saskatchewan in a study where residents were asked whether they experienced difficulties with access to medical or surgical specialist care. Rural residents reported between $16 \%$ and $45 \%$ increased perceived difficulties with access to care. ${ }^{45}$ Consistent with our findings, a review of the literature suggested that rural residence

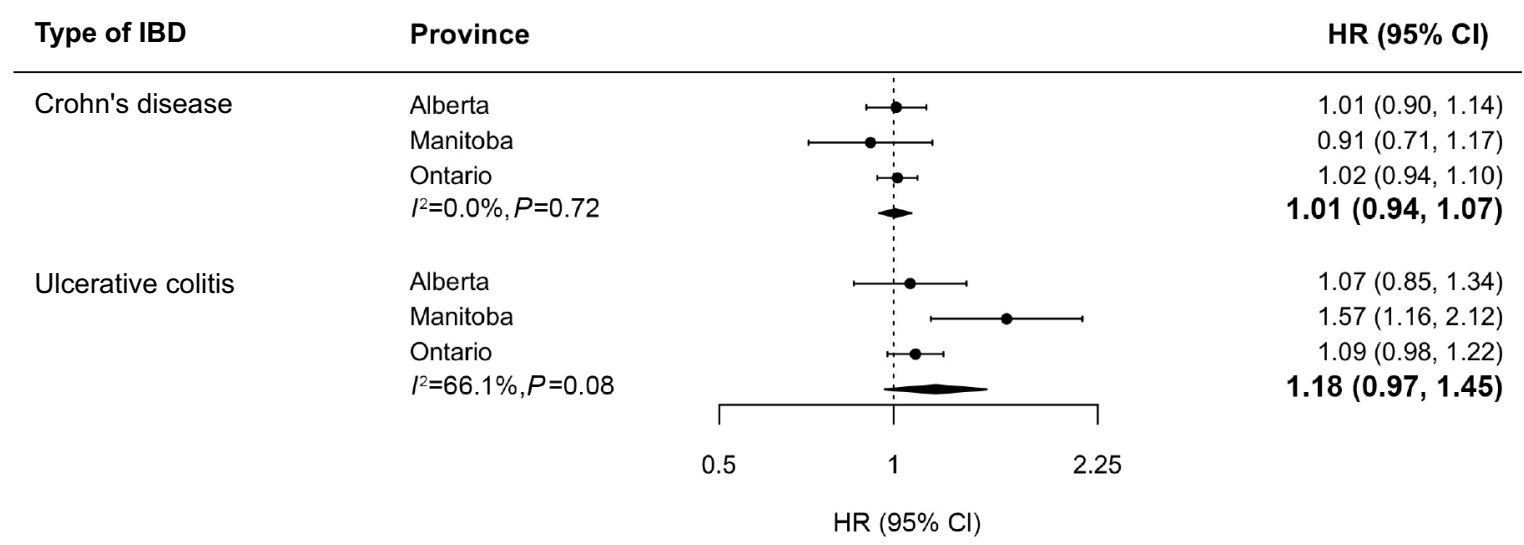

Figure 5 Association between rural and urban (reference) residences and prediagnostic lag time (multivariable Cox proportional hazard models). Bolded values represent meta-analysis results.

Abbreviation: IBD, inflammatory bowel disease. 


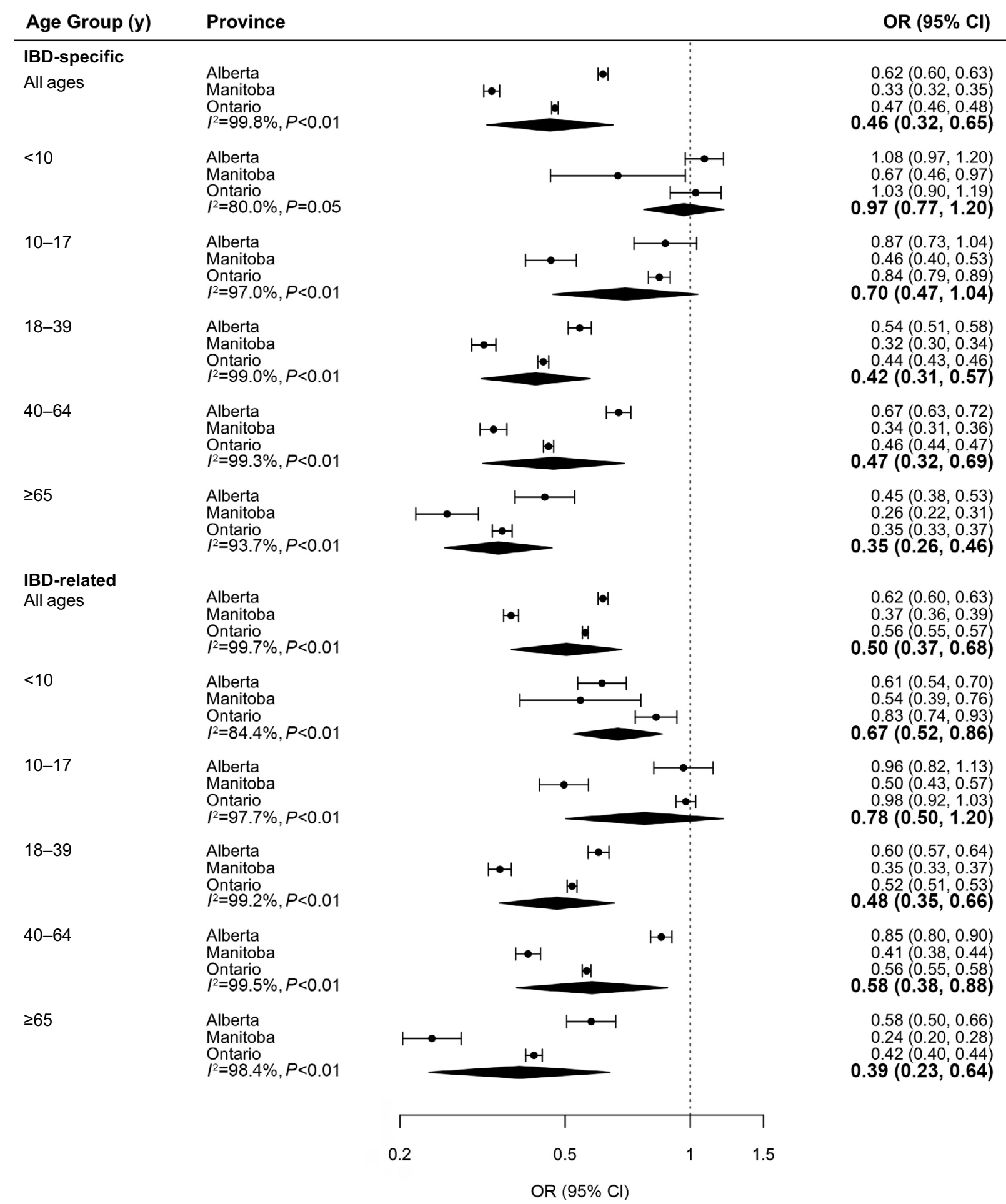

Figure 6 Association between rural and urban (reference) residences and likelihood of ever having seen a gastroenterologist for IBD-specific or IBD-related care (multivariable logistic regression models). Bolded values represent meta-analysis results.

Abbreviation: IBD, inflammatory bowel disease.

played a significant role in determining the nature and level of access to health services, but it did not always translate into health disadvantages, especially when controlling for other sociodemographic factors. ${ }^{46}$
A recent Canadian study demonstrated that people living in rural residence were less likely to develop IBD, with a particularly strong protective effect of rurality in childhood. ${ }^{47}$ Any study related to disease incidence using health 

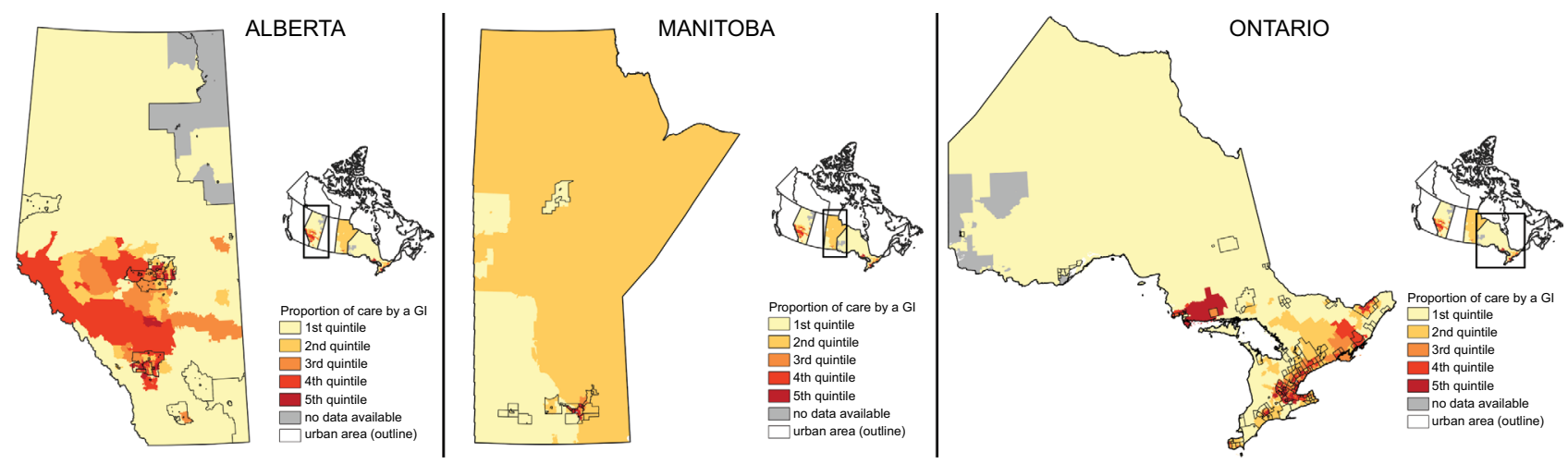

Figure 7 Heat map demonstrating that higher proportion of IBD care provided by gastroenterologists (darker colors) was more likely to be located in urban regions (outlined boxes).

Abbreviation: $\mathrm{Gl}$, gastroenterologist; IBD, inflammatory bowel disease.

Table 2 Models to determine whether specialist care provision mediated the relationship between rural/urban residence and disparities in health services utilization in Ontario IBD patients

\begin{tabular}{|c|c|c|c|c|}
\hline $\begin{array}{l}\text { Health services } \\
\text { measure }\end{array}$ & $\begin{array}{l}\text { Original model, } \\
\text { adjusted IRR/OR/HR } \\
(95 \% \mathrm{CI})\end{array}$ & $\begin{array}{l}\text { Specialist care } \\
\text { definition \# I, } \\
\text { adjusted IRR/OR/HR } \\
(95 \% \mathrm{Cl})\end{array}$ & $\begin{array}{l}\text { Specialist care } \\
\text { definition \# 2, } \\
\text { adjusted IRR/OR/HR } \\
(95 \% \mathrm{Cl})\end{array}$ & $\begin{array}{l}\text { Specialist care } \\
\text { definition \# 3, } \\
\text { adjusted IRR/OR/HR } \\
(95 \% \mathrm{Cl})\end{array}$ \\
\hline \multicolumn{5}{|c|}{ Outpatient visit rate } \\
\hline IBD-specific & $0.96(0.92-0.99)$ & $0.97(0.93-1.00)$ & $0.97(0.93-1.00)$ & $1.005(0.97-1.04)$ \\
\hline IBD-related & $0.93(0.90-0.96)$ & $0.92(0.89-0.95)$ & $0.92(0.89-0.95)$ & $0.95(0.91-0.98)$ \\
\hline \multicolumn{5}{|l|}{ Hospitalization rate } \\
\hline IBD-specific & $\mathrm{I} .04(0.97-\mathrm{I} . \mathrm{II})$ & $1.01(0.95-1.08)$ & $\mathrm{I} .00(0.94-\mathrm{I} .07)$ & $1.08(1.01-1.15)$ \\
\hline IBD-related & $1.06(0.99-I .12)$ & $1.02(0.96-1.09)$ & I.0I (0.95-I.07) & $1.07(1.01-1.14)$ \\
\hline \multicolumn{5}{|c|}{ Risk of hospitalization } \\
\hline IBD-specific & I.0I (0.95-I.07) & $0.97(0.92-1.03)$ & $0.97(0.91-1.03)$ & $1.04(0.98-I .10)$ \\
\hline IBD-related & I.03 (0.98-I.09) & $0.99(0.94-1.05)$ & $0.98(0.93-1.04)$ & I.04 (0.99-I.I0) \\
\hline \multicolumn{5}{|l|}{ ED visit rate } \\
\hline IBD-specific & $1.53(1.42-1.65)$ & 1.47 (I.36-I.59) & 1.45 (I.34-I.56) & 1.55 (I.44-I.67) \\
\hline IBD-related & $1.33(1.25-1.40)$ & $1.26(1.19-1.33)$ & $1.24(1.17-1.31)$ & $1.30(1.23-1.38)$ \\
\hline \multicolumn{5}{|l|}{ Risk of ED visit } \\
\hline IBD-specific & $1.23(1.16-1.31)$ & $1.19(1.12-1.26)$ & $1.18(1.11-1.25)$ & $1.25(1.17-1.32)$ \\
\hline IBD-related & $1.16(1.11-1.21)$ & $1.11(1.06-1.17)$ & $1.10(1.05-1.15)$ & I.I 5 (I.09-I.2I) \\
\hline
\end{tabular}

Notes: Bolded results: statistically significant. Original model: no specialist care measure included as independent variable. Specialist care definition \# I: included whether patient had gastroenterologist as primary IBD care provider ( $>50 \%$ of IBD-specific visits) as independent variable. Specialist care definition \# 2: included the proportion of IBD-specific care provided by a gastroenterologist as independent variable. Specialist care definition \# 3: included whether patient had ever seen a gastroenterologist within the first 6 months of diagnosis as independent variable. Bolded results were statistically significant $(P<0.05)$.

Abbreviations: ED, emergency department; HR, hazard ratio; IBD, inflammatory bowel disease; IRR, incidence rate ratio; OR, odds ratio.

administrative data is subject to potential risk of bias related to access to health services. Our finding that rural and urban IBD patients had similar outpatient health services utilization both before and after diagnosis is reassuring, as it implies that the difference in incidence among rural and urban patients was not secondary to lower outpatient visit rates in the rural population.

The use of health administrative data, while populationbased and allowing for a large cohort size, may have resulted in some limitations. While we used identification algorithms to identify IBD patients validated in $\mathrm{AB},{ }^{25} \mathrm{MB},{ }^{26}$ and $\mathrm{ON},{ }^{27,28}$ the risk of misclassification is possible, especially resulting from differential accuracy of these algorithms in rural or urban patients. The algorithms were validated in a variety of populations, including in communities remote from urban centers. Considering the lower incidence of IBD in rural residence described in previous research, ${ }^{47}$ it is unlikely that the algorithms resulted in differential misclassification of rural people as having IBD when they did not. However, codes used to identify prediagnostic health care contacts 
related to IBD were based on expert opinion of clinicians and researchers and were not validated. Based on the opinion of the experts, we chose only codes that were highly related to subsequent diagnosis with IBD and limited prediagnostic time to 5 years. This may have resulted in misclassification of time to diagnosis. Other potential confounders such as tobacco smoking status, disease extent, and severity were not available within health administrative data. Finally, there may be other social, cultural, or clinical factors, which may have contributed to our findings.

Some of our results underscore other limitations of using health administration data for research purposes. One important limitation is the lack of phenotype, severity, or other clinical characteristics of IBD. Rural residents may still experience poor access to care and outcomes, but they may also have more severe disease, resulting in a masking of disparities in access. However, we have no indication that people in rural residence have a different phenotype or severity from those living in urban communities. In addition, it is uncertain if the increased rates of hospitalization or ED visits in rural Canada reflect increased disease severity or an inappropriate use of hospitalizations in the management of IBD. The similar rates of IBD-related surgeries and multiple surgeries support the possibility that there is a potentially unnecessary excess in rural hospitalizations for IBD. However, the visits may be related to the model of care in underserviced communities. For example, patients may access care by their family physician working in the ED, as many rural family physicians also cover ED shifts in local hospitals. While this would not result in inappropriate primary care, the visit would still be excessively expensive since it would require the resources provided to EDs. This requires further consideration by health care administrators concerned with limiting expenditures.

Furthermore, care provision by a gastroenterologist did not mediate the association between rural residence and increased ED visits. Since these ED visits did not result in increased hospitalization in rural patients, they were more likely of lower acuity and thus manageable in the outpatient setting. This suggests that specialist care has not reduced expensive, undesirable health care utilization. However, it is possible that gastroenterologists saw the most ill of IBD patients. Hence, these patients are more likely to use the ED; yet they are no more likely to be hospitalized because of the proactive care provided. In a separate study using MB health administrative data, visits with a gastroenterologist within the prior year significantly reduced ED attendance among incident cases. ${ }^{48}$ Incident cases typically have more severe illness, and hence this supports the notion that gastroenterologist care can reduce health care utilization in IBD. In the MB study, gastroenterologist care did not reduce $\mathrm{ED}$ attendance by prevalent IBD cases, nor did it reduce hospitalization among those who did attend the ED. These findings are confounded by issues of disease severity that could not be addressed within the limits of either study. Future research should combine qualitative and quantitative methods in specific groups in rural communities that may experience poor access to care or different outcomes from urban patients. In addition, future research should focus on elderly patients with IBD to determine why differences in use of gastroenterologist care were so pronounced in rural/ urban patients of that age group.

\section{Conclusion}

Rural residents of Canada with IBD had increased hospitalization and ED visit rates compared to urban patients; yet they had similar outpatient visit rates, surgical risk, and diagnostic delay compared to urban residents. There were lower rates of gastroenterologist physician visits in rural patients, particularly by older people. Therefore, rural patients had decreased use of specialist care. While this did not result in long-term clinical outcomes (surgery), this may be associated with more expensive use of the health system (ED visits and hospitalizations). In studying a universal health care system, we remove insurance access as a crucial factor. This study implies that clinicians and health policy makers should consider ways in which to avoid expensive, undesirable health services utilization in rural IBD patients. Innovative methods of delivering care to these patients (such as telehealth, online care by IBD specialists, and remote clinics) should be explored.

\section{Data sharing statement}

The ON data set from this study is held securely in coded form at ICES. While data sharing agreements prohibit ICES from making the data set publicly available, access may be granted to those who meet prespecified criteria for confidential access, available at www.ices.on.ca/DAS. The full data set creation plan and underlying analytic code are available from the authors upon request, understanding that the programs may rely upon coding templates or macros that are unique to ICES.

\section{Acknowledgments}

The abstract of this article was presented at the Canadian Digestive Diseases Week 2018 and Digestive Disease Week 2018 as posters with interim findings. The poster's abstract was published in preliminary form in the Journal of the Canadian Association of Gastroenterology (https://doi.org/10.1093/jcag/ gwy009.031) and Gastroenterology (https://doi.org/10.1016/ 
S0016-5085(15)30006-8). Elements of the data analysis were corrected since publication of these abstracts. The authors would like to thank Danielle Birman and Shabnaz Siddiq who acted as research coordinators for CanGIEC. This research was funded by an unrestricted, peer-reviewed operating grant from the Janssen Future Leaders in IBD Program and a Foundation Grant from the Canadian Institutes of Health Research (CIHR). This study is based in part on data provided by Alberta Health and Manitoba Health. The interpretation and conclusions contained herein are those of the researchers and do not necessarily represent the views of the Governments of Alberta and Manitoba. Neither the Government of Alberta nor Alberta Health expressed any opinion in relation to this study. This study was supported by the Institute for Clinical Evaluative Sciences (ICES), which is funded by an annual grant from the Ontario Ministry of Health and Long-Term Care (MOHLTC). The opinions, results, and conclusions reported in this article are those of the authors and are independent from the funding sources. No endorsement by ICES or the ON MOHLTC is intended or should be inferred.

\section{Disclosure}

Eric I Benchimol and Geoffrey C Nguyen were supported by New Investigator Awards from CIHR, Crohn's and Colitis Canada, and the Canadian Association of Gastroenterology. Eric I Benchimol was also supported by the Career Enhancement Program from the Canadian Child Health Clinician Scientist Program. M Ellen Kuenzig was supported by a PostDoctoral Fellowship Award from CIHR, Crohn's and Colitis Canada, and the Canadian Association of Gastroenterology. Charles N Bernstein was supported in part by the Bingham Chair in Gastroenterology. Geoffrey C Nguyen and Gilaad G Kaplan were CIHR Embedded Clinician Research Chairs. Astrid Guttmann was supported by a CIHR Applied Chair in Reproductive and Child Health Services and Policy Research. Lisa M Lix was supported by a Canada Research Chair (Tier I). The authors report no other conflicts of interest in this work.

\section{References}

1. Justice Laws Website [webpage on the Internet]. Canada Health Act. R.S.C., 1985, c. C-6; 1985. Available from: http://laws-lois.justice.gc.ca/ eng/acts/C-6/. Accessed July 8, 2017.

2. Benchimol EI, To T, Griffiths AM, Rabeneck L, Guttmann A. Outcomes of pediatric inflammatory bowel disease: socioeconomic status disparity in a universal-access healthcare system. J Pediatr. 2011;158(6):60-967. e1-4.

3. Rumman A, Candia R, Sam JJ, et al. Public versus Private Drug Insurance and Outcomes of Patients Requiring Biologic Therapies for Inflammatory Bowel Disease. Can J Gastroenterol Hepatol. 2017;2017:7365937.
4. Benchimol E, Boualit M, Wong J, Colombel J-F, Gower-Rousseau C. Predictors of the need for second intestinal resection in children with Crohn's disease. Inflamm Bowel Dis. 2011;17:S6.

5. Chassin MR, Galvin RW. The urgent need to improve health care quality. Institute of Medicine National Roundtable on Health Care Quality. JAMA. 1998;280(11):1000-1005.

6. Institute of Medicine. Crossing the Quality Chasm: A New Health System for the 21st Century. Washington, DC: National Academies Press; 2001.

7. Berwick DM. As Good As It Should Get: Making Health Care Better in the New Millennium. Washington, DC: The National Coalition on Health Care; 1988.

8. Statistics Division [webpage on the Internet]. Population Density and Urbanization: Yearbook 2015. Table 3: Population by Sex, Annual Rate of Population Increase, Surface Area and Density; 2015. Available from: https://unstats.un.org/unsd/demographic/products/dyb/dyb2015.htm. Accessed July 8, 2017.

9. Riva M, Curtis S, Gauvin L, Fagg J. Unravelling the extent of inequalities in health across urban and rural areas: evidence from a national sample in England. Soc Sci Med. 2009;68(4):654-663.

10. Booth GL, Hux JE, Fang J, Chan BT. Time trends and geographic disparities in acute complications of diabetes in Ontario, Canada. Diabetes Care. 2005;28(5):1045-1050.

11. Molodecky NA, Soon IS, Rabi DM, et al. Increasing incidence and prevalence of the inflammatory bowel diseases with time, based on systematic review. Gastroenterology. 2012;142(1):46-54, e42.

12. Benchimol EI, Fortinsky KJ, Gozdyra P, van den Heuvel M, van Limbergen J, Griffiths AM. Epidemiology of pediatric inflammatory bowel disease: a systematic review of international trends. Inflamm Bowel Dis. 2011;17(1):423-439.

13. Ng SC, Shi HY, Hamidi N, et al. Worldwide incidence and prevalence of inflammatory bowel disease in the 21 st century: a systematic review of population-based studies. Lancet. 2017;390(10114):2769-2778.

14. Benchimol EI, Bernstein CN, Bitton A, et al. Trends in Epidemiology of Pediatric Inflammatory Bowel Disease in Canada: Distributed Network Analysis of Multiple Population-Based Provincial Health Administrative Databases. Am J Gastroenterol. 2017;112(7):1120-1134.

15. Kaplan GG. The global burden of IBD: from 2015 to 2025. Nat Rev Gastroenterol Hepatol. 2015;12(12):720-727.

16. Coward S, Clement F, Benchimol EI, et al. The rising prevalence of inflammatory bowel disease in Canada: analyzing the past to predict the future. J Canadian Assoc Gastroenterol. 2018;1(Suppl 2):47-48.

17. Statistics Canada [webpage on the Internet]. Population by Year, by Province and Territory (Number); 2016. Available from: http://www. statcan.gc.ca/tables-tableaux/sum-som/101/cst01/demo02a-eng.htm. Accessed July 8, 2017.

18. du Plessis V, Beshiri R, Bollman RD, Clemenson H. Definitions of "Rural". Ottawa, ON: Statistics Canada; December 1 2002. 21-601MIE - No. 061.

19. Statistics Canada [webpage on the Internet]. Population, Urban and Rural, by Province and Territory; 2011. Available from: http://www. statcan.gc.ca/tables-tableaux/sum-som/101/cst01/demo62a-eng.htm. Accessed January 8, 2016.

20. Benchimol EI, Guttmann A, To T, Rabeneck L, Griffiths AM. Changes to surgical and hospitalization rates of pediatric inflammatory bowel disease in Ontario, Canada (1994-2007). Inflamm Bowel Dis. 2011;17(10): 2153-2161.

21. Benchimol EI, Mack DR, Nguyen GC, et al. Incidence, outcomes, and health services burden of very early onset inflammatory bowel disease. Gastroenterology. 2014;147(4):803-813.e7.

22. Ma C, Crespin M, Proulx MC, et al. Postoperative complications following colectomy for ulcerative colitis: a validation study. $B M C$ Gastroenterol. 2012;12:39.

23. Ma C, Moran GW, Benchimol EI, et al. Surgical Rates for Crohn's Disease are Decreasing: A Population-Based Time Trend Analysis and Validation Study. Am J Gastroenterol. 2017;112(12):1840-1848. 
24. Benchimol EI, Manuel DG, Mojaverian N, et al. Health Services Utilization, Specialist Care, and Time to Diagnosis with Inflammatory Bowel Disease in Immigrants to Ontario, Canada: A Population-Based Cohort Study. Inflamm Bowel Dis. 2016;22(10):2482-2490.

25. Rezaie A, Quan H, Fedorak RN, Panaccione R, Hilsden RJ. Development and validation of an administrative case definition for inflammatory bowel diseases. Can J Gastroenterol. 2012;26(10):711-717.

26. Bernstein CN, Blanchard JF, Rawsthorne P, Wajda A. Epidemiology of Crohn's disease and ulcerative colitis in a central Canadian province: a population-based study. Am J Epidemiol. 1999;149(10):916-924.

27. Benchimol EI, Guttmann A, Griffiths AM, et al. Increasing incidence of paediatric inflammatory bowel disease in Ontario, Canada: evidence from health administrative data. Gut. 2009;58(11):1490-1497.

28. Benchimol EI, Guttmann A, Mack DR, et al. Validation of international algorithms to 0identify adults with inflammatory bowel disease in health administrative data from Ontario, Canada. J Clin Epidemiol. 2014;67(8):887-896.

29. Statistics Canada. Postal Code ${ }^{O M}$ Conversion File (PCCF), Reference Guide, 2013. Ottawa, ON: Statistics Canada; 2013.

30. Canadian Institute for Health Information. CIHI Data Quality Study of the 2009-2010 Discharge Abstract Database. Ottawa, ON: Canadian Institute for Health Information, Standards and Data Submission; 2012.

31. Soon IS, Wrobel I, Debruyn JC, et al. Postoperative complications following colectomy for ulcerative colitis in children. J Pediatr Gastroenterol Nutr. 2012;54(6):763-768.

32. Wilkins R. PCCF+Version 4E User's Guide: Automated Geographic Coding Based on the Statistics Canada Postal Code Convesion Files, Including Postal Codes to July 2004. Ottawa, ON: Health Analysis and Measurement Group, Statistics Canada. Catalogue No. 93-387-XIE; 2005.

33. ICES Data Dictionary [webpage on the Internet]. ICES Physician Database (IPDB); 2016. Available from: https://datadictionary.ices.on.ca/ Applications/DataDictionary/Library.aspx?Library=IPDB. Accessed January 4, 2016.

34. Glazier RH, Creatore MI, Agha MM, Steele LS; Inner City Toronto Time Trends Working Group. Socioeconomic misclassification in Ontario's Health Care Registry. Can J Public Health. 2003;94(2):140-143.

35. Timmer A, Behrens R, Buderus S, et al. Childhood onset inflammatory bowel disease: predictors of delayed diagnosis from the CEDATA German-language pediatric inflammatory bowel disease registry. J Pediatr. 2011;158(3):467-473.e2.
36. Porta M, Gallén M, Malats N, Planas J. Influence of "diagnostic delay" upon cancer survival: an analysis of five tumour sites. J Epidemiol Community Health. 1991;45(3):225-230.

37. Singh $\mathrm{H}$, de Coster C, Shu E, et al. Wait times from presentation to treatment for colorectal cancer: a population-based study. Can J Gastroenterol. 2010;24(1):33-39.

38. Guevara JP, Berlin JA, WolfFM. Meta-analytic methods for pooling rates when follow-up duration varies: a case study. BMC Med Res Methodol. 2004;4:17.

39. Viechtbauer W. Conducting Meta-Analyses in $R$ with the metafor Package. J Stat Softw. 2010;36(3):1-48.

40. Borren NZ, Conway G, Tan W, et al. Distance to Specialist Care and Disease Outcomes in Inflammatory Bowel Disease. Inflamm Bowel Dis. 2017;23(7):1234-1239.

41. Lange A, Prenzler A, Bachmann O, et al. Regional differences in health care of patients with inflammatory bowel disease in Germany. Health Econ Rev. 2015;5(1):29.

42. Strasser R, Neusy AJ. Context counts: training health workers in and for rural and remote areas. Bull World Health Organ. 2010;88(10): $777-782$.

43. Murthy SK, Steinhart AH, Tinmouth J, Austin PC, Nguyen GC. Impact of gastroenterologist care on health outcomes of hospitalised ulcerative colitis patients. Gut. 2012;61(10):1410-1416.

44. Nguyen GC, Nugent Z, Shaw S, Bernstein CN. Outcomes of patients with Crohn's disease improved from 1988 to 2008 and were associated with increased specialist care. Gastroenterology. 2011;141(1):90-97.

45. Karunanayake CP, Rennie DC, Hagel L, et al. Access to Specialist Care in Rural Saskatchewan: The Saskatchewan Rural Health Study. Healthcare. 2015;3(1):84-99.

46. Smith KB, Humphreys JS, Wilson MG. Addressing the health disadvantage of rural populations: how does epidemiological evidence inform rural health policies and research? Aust J Rural Health. 2008;16(2):56-66.

47. Benchimol EI, Kaplan GG, Otley AR, et al. Rural and Urban Residence During Early Life is Associated with Risk of Inflammatory Bowel Disease: A Population-Based Inception and Birth Cohort Study. Am J Gastroenterol. 2017;112(9):1412-1422.

48. Nugent Z, Singh H, Targownik LE, Strome T, Snider C, Bernstein CN. Predictors of Emergency Department Use by Persons with Inflammatory Bowel Diseases: A Population-based Study. Inflamm Bowel Dis. 2016;22(12):2907-2916.
Clinical Epidemiology

\section{Publish your work in this journal}

Clinical Epidemiology is an international, peer-reviewed, open access, online journal focusing on disease and drug epidemiology, identification of risk factors and screening procedures to develop optimal preventative initiatives and programs. Specific topics include: diagnosis, prognosis, treatment, screening, prevention, risk factor modification,

\section{Dovepress}

systematic reviews, risk and safety of medical interventions, epidemiology and biostatistical methods, and evaluation of guidelines, translational medicine, health policies and economic evaluations. The manuscript management system is completely online and includes a very quick and fair peer-review system, which is all easy to use. 